\title{
Amygdalar NMDA Receptors Are Critical for the Expression of Multiple Conditioned Fear Responses
}

\author{
Hongjoo J. Lee, ${ }^{1}$ June-Seek Choi, ${ }^{1}$ Thomas H. Brown, ${ }^{1,2,3}$ and Jeansok J. Kim ${ }^{1,3}$

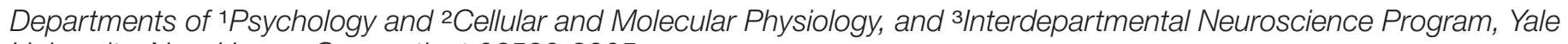 \\ University, New Haven, Connecticut 06520-8205
}

There is conflicting evidence regarding the issue of whether NMDA receptors in the basolateral amygdalar complex (BLA) are critically involved in the expression of conditioned fear. This matter was addressed by infusing the rat BLA with D,L-2-amino5-phosphonovaleric acid (APV), a competitive NMDA receptor antagonist. APV infusion into the BLA was reported to block the expression of conditioned fear when measured by freezing but not when measured by fear-potentiated startle response to a loud noise. To examine this issue further, here we used multiple indices of conditioned fear, including analgesia, $22 \mathrm{kHz}$ ultrasonic vocalization (USV), defecation, and freezing. Rats with bilateral BLA cannula implants underwent fear conditioning consisting of 10 tone-footshock pairings. Before context and tone fear-retention tests, animals received intra-BLA infusions with APV $(2.5 \mu \mathrm{g} / \mathrm{side})$ or artificial CSF. Both tone and context tests demonstrated that the expression of conditioned freezing, USV, defecation, and analgesia were significantly impaired by intra-amygdalar infusions of APV. In a second set of experiments, intra-BLA infusions of APV markedly impaired the normal expression of postshock fear responses during training, as measured by freezing, USV, and defecation. Immediate postshock fear expression was predictive of subsequent fear retention to the tone and context when the animals were not infused. These results are consistent with the hypothesis that amygdalar NMDA receptors participate in normal synaptic transmission and therefore the overall functioning of the amygdala.

Key words: learning; memory; amygdala; LTP; fear conditioning; synaptic plasticity; emotion
Long-term synaptic potentiation (LTP) is commonly suggested as a candidate neurophysiological mechanism through which acquired fear is encoded in the amygdala (Chapman et al., 1990; Kim et al., 1991; Davis et al., 1993; Lam et al., 1996; Maren and Fanselow, 1996; LeDoux, 2000). This idea was based in part on the demonstration of LTP in the amygdala in vitro (Chapman et al., 1990) and in vivo (Clugnet and LeDoux, 1990), as well as on extensive synaptic studies of the hippocampus, in which it has been shown that associative LTP exists (Barrioneuvo and Brown, 1983); this LTP is governed by a Hebbian (Hebb, 1949) mechanism (Kelso et al., 1986), and this Hebbian form of associative LTP has some of the ingredients required to construct a platform for Pavlovian conditioning (Kelso and Brown, 1986; Brown et al., 1990).

A once tenable belief was that the NMDA subtype of glutamate ionotropic receptor (NMDAR) was essential for inducing LTP, but that it had no role in the expression of LTP or normal synaptic transmission (Collingridge et al., 1983; Teyler and DiScenna, 1987; Morris et al., 1990). In this case, a suitable NMDAR antagonist might conceivably block the acquisition of conditioned fear without having any effect on its expression. The idea that amygdalar LTP might participate in fear conditioning was supported by numerous studies reporting that intra-amygdalar infu-

Received Nov. 27, 2000; revised March 2, 2001; accepted March 21, 2001.

This work was supported by the Whitehall Foundation, by Grant NIA P60AG10469 from the Claude D. Pepper Older Americans Independence Center, and by a Yale Junior Faculty Fellowship (J.J.K.) and National Institute of Mental Health Grant MH58405 (T.H.B.). We thank Markus Fendt for sharing his data and Kevin B. Baker for his assistance in the analgesia experiment.

Correspondence should be addressed to Jeansok J. Kim, Department of Psychology, 2 Hillhouse Avenue, Yale University, New Haven, CT 06520-8205. E-mail: jeansok.kim@yale.edu.

Copyright (C) 2001 Society for Neuroscience 0270-6474/01/214116-09\$15.00/0 sions of the competitive NMDAR antagonist D,L-2-amino-5phosphonovaleric acid (APV) effectively blocked the acquisition of fear conditioning (Miserendino et al., 1990; Campeau et al., 1992; Fanselow and Kim, 1994; Maren et al., 1996).

The receptor mechanisms responsible for the induction and expression of amygdalar LTP remain uncertain and may depend on the particular synapses and input pathway (Chapman et al., 1990; Weisskopf and LeDoux, 1999; LeDoux, 2000), as demonstrated in the hippocampus (Harris and Cotman, 1986; Brown et al., 1989; Grover and Teyler, 1990; Zalutsky and Nicoll, 1990; Johnston et al., 1992). One report (Chapman and Bellavance, 1992) suggested that APV can interfere with LTP induction in the basolateral amygdalar complex (BLA), but only in such high concentrations that the drug markedly impaired normal synaptic transmission (but see Huang and Kandel, 1998). Similarly, singleunit recordings indicate that normal auditory-evoked responses in the amygdala are considerably attenuated by APV, suggesting that NMDARs are involved in normal synaptic transmission of the auditory pathway to the amygdala that putatively mediates auditory fear conditioning ( $\mathrm{Li}$ et al., 1995). These results were foreshadowed and are reinforced by APV studies on the visual cortex, in which APV was found to substantially interfere with normal synaptic transmission (Miller et al., 1989; Shatz 1990).

These data notwithstanding, two reports have concluded that APV infusions into the amygdala have virtually no effect on the expression of conditioned fear, as measured by fear-potentiated startle responses to a loud noise (Miserendino et al., 1990; Campeau et al., 1992). However, two subsequent studies did find a significant impairing effect of APV on the expression of conditioned fear, as measured by freezing (Maren et al., 1996; Lee and Kim, 1998). Attempting to reconcile these disparate findings, Lee and Kim (1998) hypothesized that there may be a divergence of 
fear conditioned response (CR) centers within the amygdala, such that NMDARs are involved in synaptic transmission mediating the expression of some measures of conditioned fear (such as freezing) but not others (such as fear-potentiated startle). The present experiments further explore this hypothesis.

\section{MATERIALS AND METHODS}

\section{Experiment 1: effects of intra-amygdalar APV on the expression of multiple conditioned fear responses}

Previous studies have found that intra-BLA infusions of APV impaired the expression of conditioned freezing to tone, light, and context conditioned stimuli (CSs) in Long-Evans rats (Maren et al., 1996; Lee and Kim, 1998). The goal of experiment 1 was to determine the NMDAR dependence of the expression of conditioned fear using four established fear measures, including analgesia (Helmstetter and Bellgowan, 1993), the $22 \mathrm{kHz}$ ultrasonic vocalization (USV) (a distress signal) (Blanchard et al., 1991), defecation (Fanselow and Kim, 1992), and freezing (Blanchard and Blanchard, 1969). As part of an ongoing study of fear conditioning in different stocks of rats, Sprague Dawley rats were used in the experiment assessing conditioned freezing, USV, and defecation, whereas Long-Evans rats were used in the conditioned analgesia experiment. These measures were used to assess conditioned fear to a specific context and a discrete tone.

Subjects. Experimentally naive male Sprague Dawley and Long-Evans rats (initially weighing 275-325 gm) were obtained from Charles River (Wilmington, MA) and housed individually in a climate-controlled vivarium on a $12 \mathrm{hr}$ light/dark cycle (lights on at 7:00 A.M.) with ad libitum access to food and water. All experiments were conducted during the light phase of the cycle and were in strict compliance with the Yale Animal Resource Center guidelines.

Surgery. All rats were anesthetized via intraperitoneal injection of a ketamine $(30 \mathrm{mg} / \mathrm{kg})$-xylazine $(2.5 \mathrm{mg} / \mathrm{kg})$ solution, with supplemental injections given as needed. Under aseptic conditions, a stereotaxic instrument (Stoelting, Wood Dale, IL) was used to implant 26 gauge guide cannulas (Plastics One Inc., Roanoke, VA) bilaterally into the BLA (from bregma: anteroposterior, $-2.3 \mathrm{~mm}$; mediolateral, $\pm 5 \mathrm{~mm}$; dorsoventral, $-7.7-8.0 \mathrm{~mm})$. Implanted cannulas were cemented to three anchoring screws on the skull. During $7 \mathrm{~d}$ of postoperative recovery, the rats were adapted to transportation and handling, and each dummy cannula was removed and replaced with a clean one.

Drugs and injection. APV (Research Biochemicals, Natick, MA), dissolved in artificial CSF (ACSF), pH 7.4, was microinf used into the BLA (bilaterally) by backloading the drug up a 33 gauge internal cannula into polyethylene (PE 20) tubing connected to $10 \mu$ l Hamilton microsyringes (Hamilton Company, Reno, NV). The internal cannula extended $1.0 \mathrm{~mm}$ beyond the guide cannula. An injection volume of $0.3 \mu \mathrm{l}$ (per side) was delivered using a Harvard PHD 2000 syringe pump (Harvard Apparatus, Inc., South Natick, MA) over the course of $3 \mathrm{~min}$ (at a rate of $0.1 \mu \mathrm{l} / \mathrm{min}$ ). The internal cannula remained in place for at least $30 \mathrm{sec}$ after the infusions before being pulled out.

Because the intra-BLA infusion parameter used in the present study is similar to those used by Davis and colleagues (Miserendino et al., 1990; Falls et al., 1992), the extent of APV diffusion in the amygdala should be reasonably comparable between these studies. In addition, our drug inf usion parameter is similar to other studies that dissociated drug effects in the BLA from the central nucleus (Fanselow and Kim, 1992; Roozendaal and McGaugh, 1997; Shors and Mathew, 1998). Hence, any effects exerted by APV on the expression of conditioned fear likely occur because of the blockade of NMDA receptors within the BLA. However, the possibility of APV spreading to and affecting immediate adjacent regions [especially the overlying lateral amygdalar nucleus (LA)] cannot be ruled out.

Fear conditioning apparatus and procedure. Training and testing took place in two modular operant test chambers, each equipped with speaker modules (Coulbourn Instruments, Allentown, PA), located in a controlled acoustic room (Industrial Acoustics Company, Inc., New York, NY). The two chambers differed in several regards: chamber A was rectangular $(27 \mathrm{~cm}$ width $\times 28 \mathrm{~cm}$ length $\times 30.5 \mathrm{~cm}$ height $)$, whereas chamber B was octagonal $(26.5 \mathrm{~cm}$ diameter $\times 25 \mathrm{~cm}$ height $)$. Chamber A had front and back walls made of clear Plexiglas and two side walls made of metal plates, whereas chamber B had all eight walls constructed of clear Plexiglas. Finally, chamber A was placed in a wooden isolation box (46 cm width $\times 53 \mathrm{~cm}$ length $\times 49 \mathrm{~cm}$ height) that was painted white, whereas chamber $\mathrm{B}$ was placed in a similar box that was painted black.
Table 1. Experimental design for the freezing, USV, and defecation experiment

\begin{tabular}{|c|c|c|}
\hline Day & Group 1 & Group 2 \\
\hline 1 & $\begin{array}{l}10 \text { tone-shock pairings in } \mathrm{A} \\
\text { (or } \mathrm{B} \text { ) }\end{array}$ & $\begin{array}{l}10 \text { tone-shock pairings } \\
\text { in } \mathrm{A} \text { (or } \mathrm{B} \text { ) }\end{array}$ \\
\hline 2 & $\begin{array}{l}\text { Context test in A (or B) with } \\
\text { ACSF }\end{array}$ & $\begin{array}{l}\text { Context test in A (or B) } \\
\text { with APV }\end{array}$ \\
\hline 3 & Context test in A (or B) & Context test in A (or B) \\
\hline 4 & Tone test in B (or A) with APV & $\begin{array}{l}\text { Tone test in B (or A) with } \\
\text { ACSF }\end{array}$ \\
\hline 5 & Tone test in $\mathrm{B}$ (or $\mathrm{A}$ ) & Tone test in B (or A) \\
\hline
\end{tabular}

A, Chamber A; B, chamber B.

The grid floor of chamber A was composed of 16 stainless steel bars (4.5 $\mathrm{mm}$ diameter) spaced $17.5 \mathrm{~mm}$ center-to-center and wired to a Coulbourn precision-regulated animal shocker. The grid floor of chamber B was composed of 17 stainless steel bars ( $5 \mathrm{~mm}$ diameter) spaced 15 $\mathrm{mm}$ apart and wired to a second, identical Coulbourn shocker. The floor grid and base pan of each chamber were washed thoroughly with tap water and dried completely before training and testing. Fecal boli were counted during training and testing days.

The experiments took place over the course of 5 consecutive days. On day 1 , rats were placed in either chamber A or chamber B (counterbalanced). Both cages were wiped with 5\% ammonium hydroxide solution, and the overhead room light was on. After $1 \mathrm{~min}$, animals were presented with 10 coterminating tone-footshock pairings (tone, $2.9 \mathrm{kHz}$, $82 \mathrm{~dB}, 10 \mathrm{sec}$; footshock, $1 \mathrm{~mA}, 1 \mathrm{sec})$ with 1 min intertrial intervals (ITIs). Animals were removed 1 min after the last shock and returned to their home cages (see Table 1 for the experimental design). On the second day, rats were inf used with either APV or ACSF and placed in the same chamber as on day 1 for 8 min of context testing. The following day, all rats underwent the same context testing as on day 2, but without infusions.

The fourth day entailed a tone-retention test in a context shift. Animals trained in chamber A were tested in chamber B and vice versa. The floor of each chamber was replaced with Plexiglas, which was scattered with sawdust. In addition, the overhead lights were turned off, and each internal chamber was wiped with a $1 \%$ acetic acid solution. These changes produced a reliable context shift. The animals that received APV on day 2 were infused with ACSF, whereas the animals that received ACSF on day 2 were inf used with APV. The tone-retention test consisted of $1 \mathrm{~min}$ of baseline followed by $8 \mathrm{~min}$ of continuous tone. On the final day, animals underwent the same tone test as on day 4 in the absence of infusions. To minimize the extent of necrosis around the cannula tip produced by multiple insertions of the injection cannula, animals were inf used before context test (day 2) and tone test (day 4), but not before context extinction test (day 3 ) and tone extinction test (day 5) (cf. Lee and Kim, 1998).

Freezing and USV data collection and analysis. The stimulus presentations were controlled and the freezing data were collected by an IBM personal computer (PC) equipped with the Coulbourn LabLinc Habitest Universal Linc System. Although the collection of the vocalization and freezing data was fully automated, each session was recorded for video and audio analysis off-line, if necessary, using an infrared light source and miniature video camera (CB-21; Circuit Specialists, Inc., Mesa, AZ).

A 24 cell infrared activity monitor that detects the movement of the emitted infrared $(1300 \mathrm{~nm})$ body-heat image from the animals in the $x$-, $y$-, and $z$-axes was mounted on top of each chamber and used to assess freezing behavior (cf. Lee and Kim, 1998). In brief, the total time of inactivity exhibited by each animal was measured using a computer program, and freezing was defined as continuous inactivity lasting $\geq 3$ sec. Any behavior that yielded an inactivity of $<3 \mathrm{sec}$ was recorded as general activity.

A heterodyne bat detector (Mini-3; Noldus Information Technology, Wageninge, The Netherlands) was used to transform high-frequency $(22 \pm 5 \mathrm{kHz})$ ultrasonic vocalizations into the audible range. The output of the bat detector was fed through an audio amplitude filter (Noldus), which filtered out signals falling below an amplitude range that was individually adjusted for each animal. The resulting signal was then sent to an IBM PC equipped with Noldus UltraVox vocalization analysis 
software. The software converted the signal into vocalization onset and offset times according to the following specifications: an onset was recorded if its duration was $\geq 30 \mathrm{msec}$, and the offset was recorded if the onset of the ensuing episode was $\geq 40 \mathrm{msec}$ apart. If the interval was $<40$ msec, the two bouts were counted as a single episode.

A custom-written analysis program was used to generate a raster plot representing the distribution of freezing and vocalization episodes over the entire session.

Conditioned analgesia apparatus and procedure. Long-Evans rats underwent 3 consecutive days of fear conditioning (without inf usions). Ten tone-footshock pairings were presented daily in the same manner as described for day 1 above. Our pilot data indicated that $3 \mathrm{~d}$ of training produced reliable conditioned analgesia to the tone CS. At 2-3 hr after the training sessions on days 1,2 , and 3 , each subject was gently restrained under a hand towel on a Tail-Flick Analgesia Meter (model 0570-001L; Columbus Instruments, Columbus, OH) for $\sim 20 \mathrm{sec}$ of adaptation, during which the tail of the animal was placed on the heat lamp source (which was turned off on days 1 and 2). This procedure was repeated four times with $\sim 30 \mathrm{sec}$ interval periods between adaptations.

On day 3 of training, all animals underwent tail-flick experiments (four measures) with the lamp intensity setting preset to 8 , which produced $\sim 10 \mathrm{sec}$ baseline tail-flick responses as measured using the automatic tail-flick detection mode. On day 4 of testing, animals were infused with either APV or ACSF into their BLA before the tail-flick responses were measured in the manner described on day 3 , the only change being that the tone CS came on 10-15 sec before the third tail-flick measure and remained on all through the fourth measure. The speaker module used during training was placed next to the tail-flick apparatus. The experimenter performing the tail-flick procedure was unaware of the drug treatment the animal had received.

Histology. At the completion of all behavioral testing, the subjects were overdosed with ketamine $\mathrm{HCl}$ and xylazine and perfused intracardially with $0.9 \%$ saline followed by $10 \%$ buffered formalin. The brains were removed and stored in $10 \%$ formalin for at least 2 weeks before slicing. Transverse sections $(80 \mu \mathrm{m})$ were taken through the extent of the cannula placement, mounted on gelatinized slides, and stained with cresyl violet dye. An observer unaware of the behavioral data determined the locations of the cannula tips, and subjects with inaccurate cannula placements were excluded from the statistical analysis.

\section{Experiment 2: effects of APV on expression of postshock fear responses and acquisition of conditioned fear}

Based on the results of experiment 1, it is clear that intra-amygdalar infusions of APV during retention tests can profoundly impair the expression of conditioned fear, as measured by freezing, USV, defecation, and analgesia. The goal of experiment 2 was to examine the effects of intra-amygdalar infusions of APV during training and to relate postshock fear responses to subsequent retention tests in which none of the animals were infused. The only precedent to this experiment was a study by Lee and Kim (1998) showing that when APV was administered to Long-Evans rats just before fear conditioning, it considerably attenuated postshock freezing during training. The relationship between postshock fear responses and subsequent performance on retention tests might potentially be relevant to the interpretation of the mechanisms of action of APV. Specifically, if intra-amygdalar APV blocks the acquisition of fear conditioning by directly interfering with normal synaptic transmission (of CS and/or US pathways) in the amygdala, then the effect of APV on postshock fear responses should correlate with the level of conditioned fear during the retention test.

Subjects, surgeries, and behavioral training. Two groups of naive Sprague Dawley male rats (275-325 gm) received bilateral cannula implants and drug infusions in a manner identical with that of experiment 1 .

On day 1 , animals were infused with either APV $(2.5 \mu \mathrm{g} / 0.3 \mu \mathrm{l}$ per side) or ACSF ( $0.3 \mu \mathrm{l}$ per side $)$ and placed in the chamber. After $1 \mathrm{~min}$, animals were presented with 10 coterminating tone-footshock pairings. The animals were removed $1 \mathrm{~min}$ after the last shock and returned to their home cages. On day 2, the animals were placed back in the trained context for $8 \mathrm{~min}$ of context testing. Animals were not infused during this testing period. On day 3 , animals were given a tone-retention test, which consisted of $1 \mathrm{~min}$ of baseline followed by $8 \mathrm{~min}$ of continuous tone. Animals did not receive infusions before the tone test.

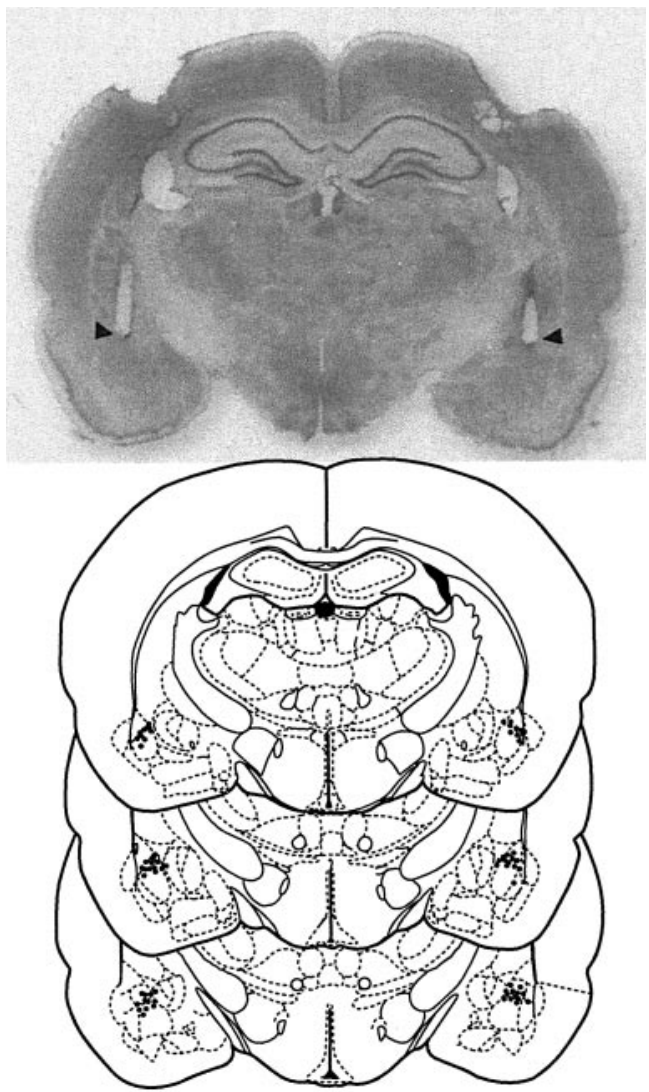

Figure 1. Top, Photomicrograph showing a transverse brain section stained with cresyl violet from a rat with bilateral guide cannulas implanted in the BLA. Arrowheads indicate guide cannula tip positions. Bottom, Location of injection sites based on a reconstruction of guide cannula placements in the BLA from experiment 1 animals.

\section{RESULTS}

\section{Experiment 1}

\section{Histology}

Figure 1 shows a photomicrograph of a transverse brain section stained with cresyl violet from a typical rat with bilateral guide cannulas implanted in or just dorsal to the BLA, as well as a composite of the injection sites based on a reconstruction of cannula placements (Paxinos and Watson, 1997).

\section{Conditioned freezing}

Figure $2 A$ depicts the mean percentage of freezing from toneshock-trained animals in both group I (open circles, $n=9$ ) and group II ( filled circles, $n=10$ ). As shown, animals in both groups exhibited robust postshock freezing during the ITIs on day 1 of inf usion-free training.

The context test (Fig. 2B) shows that group II animals (which received intra-amygdalar infusions of APV before context testing) showed significantly impaired freezing (on day 2) in comparison with the group I animals that received ACSF infusion $\left(F_{(1,17)}=61.45 ; p<0.01\right)$. When retested in the same context in the absence of infusions (on day 3 ), group II animals (which had received APV infusions on day 2 ) now froze significantly more than they did on day $2\left(F_{(1,9)}=15.08 ; p<0.01\right)$. In contrast, group I animals (which had received an ACSF infusion on day 2) exhibited greater freezing on day 2 than on day $3\left(F_{(1,8)}=6.21\right.$; $p<0.05)$. This pattern is consistent with selectively impaired day 

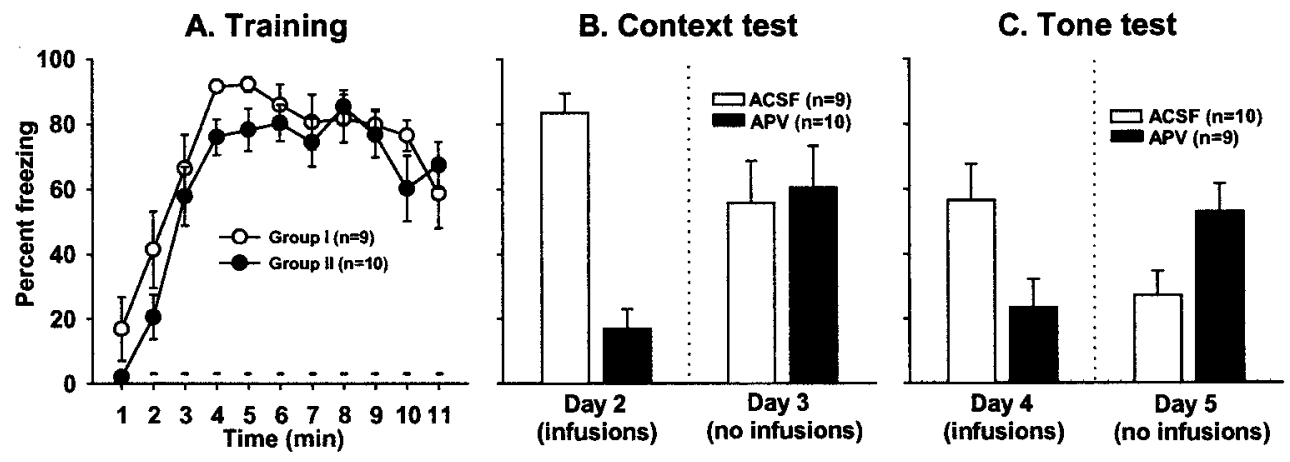

Figure 2. A, Mean percentage of freezing ( \pm SE) during the 1 min baseline and during the intervening 10 tone-shock pairings (denoted by small bars) of the 1 min ITIs with no inf usions. Group I received ACSF during the context test and APV during the tone test, whereas group II received APV during the context test and ACSF during the tone test. $B$, Mean percentage of freezing ( \pm SE) during 8 min context-retention testing after intra-BLA inf usions of ACSF or APV (Day 2) and during 8 min context retesting the next day (Day 3). C, Mean percentage of freezing ( \pm SE) during an 8 min tone-retention test in context B after intra-BLA infusions of ACSF or APV (Day 4) and during a tone retest the next day (Day 5).

2 extinction in APV-infused animals and is supported by a significant interaction between the drug treatment and the testing day $\left(F_{(1,17)}=20.22 ; p<0.01\right)$.

The tone test (Fig. $2 C$ ) shows that the animals that received APV infusions before retention testing demonstrated significantly attenuated freezing in comparison with the animals that received $\operatorname{ACSF}\left(F_{(1,17)}=5.80 ; p<0.05\right)$. When retested to the tone without infusions (on day 5), the animals that had received APV on the previous tone test froze considerably more than the animals that received ACSF on the previous tone test $\left(F_{(1,17)}=\right.$ $4.56 ; p<0.05)$. Again, there was a significant interaction between the drug treatment and the testing day $\left(F_{(1,17)}=19.60 ; p<0.01\right)$, consistent with the hypothesis that APV blocks extinction during the tone test on day 4.

To appreciate better the impairing effects of intra-BLA APV on the expression of conditioned fear across time, Figure 3 displays freezing as event raster plots that show the distribution of freezing episodes (raw data) from a typical APV and ACSF animal during context and tone tests. Here and elsewhere we operationally define the term "typical" to denote that the animal was selected on the basis that its performance was at the median of the distribution for its group. Each point on the raster plot represents an episode of freezing. Note that no subjectivity entered into these dramatic differences in freezing, which were scored by the apparatus as indicated earlier, and that these results are genuinely representative in the operationally defined sense described above.

\section{Conditioned USV}

Figure $4 A$ depicts the mean duration of USV from tone-shocktrained animals in both group I (open circles) and group II ( filled circles). As indicated, animals in both groups exhibited robust postshock USV during day 1 of infusion-free training.

The context test (Fig. 4B) shows that group II animals (which received intra-amygdalar infusions of APV before testing) showed significantly impaired USV (on day 2 ) in comparison with the group I animals (which received ACSF inf usion) $\left(F_{(1,17)}=\right.$ 26.55; $p<0.01)$. When retested in the same context in the absence of infusions (on day 3), group II animals (which had received APV on day 2) produced significantly more vocalizations than they had on day $2\left(F_{(1,9)}=6.22 ; p<0.05\right)$. In contrast, group I animals (which had received an ACSF infusion on day 2) generated significantly more USV on day 2 than on day $3\left(F_{(1,8)}\right.$ $=18.96 ; p<0.01)$. Once again, this pattern is consistent with selectively impaired day 2 extinction in the APV-infused animals and is supported by a significant interaction between drug treatment and testing day $\left(F_{(1,17)}=19.54 ; p<0.01\right)$.

The tone test (Fig. $4 C$ ) shows that the animals that received APV infusions before retention testing demonstrated significantly attenuated USV in comparison with the animals that received $\operatorname{ACSF}\left(F_{(1,17)}=22.90 ; p<0.01\right)$. When retested to the tone in the same context without infusions (day 5), the animals that had received APV on the previous tone tests generated significantly more USV than the animals that had received ACSF on the previous tone test $\left(F_{(1,17)}=6.87 ; p<0.05\right)$. Again, there was a significant interaction between the drug treatment and the testing day $\left(F_{(1,17)}=35.07 ; p<0.01\right)$, consistent with the hypothesis that APV blocks extinction during the tone test on day 4.

The impairing effects of intra-BLA infusions of APV on the expression of conditioned USV and extinction are depicted in Figure 5 as raster plots. Once again, these results are from typical rats, meaning that the animals were selected on the basis that their performance was at the median of the distribution for the group. The raster plot shows a typical ACSF and APV animal during the context test with infusions (day 2) and without infusions (day 3) (Fig. 5A) and a typical ACSF and APV animal during the tone test with infusions (day 4) and without infusions (day 5) (Fig. 5B). Overall, the USV results closely parallel freezing results (Fig. 2) and indicate that intra-BLA infusions of APV block the expression of the conditioned USV response to the tone and context stimuli and also impede extinction.

\section{Conditioned defecation}

Figure 6 depicts the mean boli counts from APV and ACSF animals during 10 pairings of tone-footshock training on day 1 (no infusions) (Fig. 6, left), during the context-retention test on day 2 (with infusions) and the context-retention retest on day 3 (no inf usions) (Fig. 6, middle), and during the tone-retention test on day 4 (with infusions) and the tone-retention retest on day 5 (no infusions) (Fig. 6, right). In both the context- and toneretention tests, intra-BLA infusions of APV significantly impaired conditioned defecation $\left(F_{(1,17)}=7.66 ; p<0.05\right.$ and $F_{(1,17)}$ $=22.23 ; p<0.01$, respectively). Furthermore, there were significant interaction effects between the drug treatment and the testing day $\left(F_{(1,17)}=13.17 ; p<0.01\right.$ for context; $F_{(1,17)}=45.61$; $p<0.01$ for tone). Thus, the defecation results parallel precisely those from freezing and USV. Again these results indicate that 
intra-BLA infusions of APV block the expression of conditioned fear to the tone and context stimuli and also impede extinction.

\section{Conditioned analgesia}

Tail-flick latencies were examined in an additional set of 19 animals. Figure 7 shows the mean tail-flick latencies from APV and ACSF animals measured before and during the tone CS presentation. As can be seen, ACSF-treated animals exhibited significantly increased latencies to tail flick (conditioned analgesia) during the tone period in comparison with the pretone period $\left(F_{(1,7)}=92.05 ; p<0.01\right)$. In contrast, APV-treated animals did not demonstrate reliably increased latencies to tail flick during the tone $\mathrm{CS}$ period when compared with the pretone period $\left(F_{(1,10)}=\right.$ $3.98 ; p>0.05)$. These conditioned analgesia results are in agreement with conditioned freezing, USV, and defecation responses and indicate that intra-BLA infusions of APV block the expression of multiple conditioned fear responses.

\section{Experiment 2}

The guide cannula tip locations were similar to those for the animals in experiment 1 (in or just dorsal to the BLA; data not shown). Intra-BLA infusions of APV produced a clear and obvious attenuation of the immediate postshock reactions of the animal to the 10 tone-footshock pairings on day 1 . Postshock freezing and USV were plotted as a function of time, whereas a cumulative measurement was obtained for defecation (Fig. 8A). Clearly, all three response measurements were dramatically attenuated during training in the APV group $(n=10)$ relative to the ACSF controls $(n=10)\left(F_{(1,18)}=45.55 ; p<0.01\right.$ for freezing; $F_{(1,18)}=23.78 ; p<0.01$ for USV; and $F_{(1,18)}=6.75 ; p<0.05$ for defecation).

The context- and tone-retention tests indicated that APV infusions into the BLA (on training day 1) dramatically blocked the acquisition of fear conditioning to the context (day 2) and the tone (day 3 ) on all three response measures (Fig. $8 B$ ): freezing to context $\left(F_{(1,18)}=38.13 ; p<0.01\right)$, USV to context $\left(F_{(1,18)}=\right.$ $12.40 ; p<0.01)$, defecation to context $\left(F_{(1,18)}=10.91 ; p<0.01\right)$, freezing to tone $\left(F_{(1,18)}=13.99 ; p<0.01\right)$, USV to tone $\left(F_{(1,18)}=\right.$ $8.76 ; p<0.01)$ and defecation to tone $\left(F_{(1,18)}=15.68 ; p<0.01\right)$.

One might expect the sizeable differences in immediate postshock responding (during training) to be predictive of or reflected in subsequent retention testing. Indeed, the immediate postshock fear responses were predictive of subsequent retention to the context and cue. Comparing training (day 1) and subsequent retention of the context (day 2 ) or tone (day 3 ), the correlations (Pearson's correlation coefficients) for all response measures were significant: freezing to context $(r=0.82 ; p<0.01)$, vocalization to context $(r=0.71 ; p<0.01)$, defecation to context $(r=0.51 ; p<$ $0.05)$, freezing to tone $(r=0.52 ; p<0.05)$, vocalization to tone $(r=$ $0.70 ; p<0.01)$, and defecation to tone $(r=0.54 ; p<0.05)$.

When examining only the APV-infused animals, the highest correlation was freezing to context $(r=0.65 ; p<0.05)$. Correlations within the APV group were clearly attenuated by a floor effect resulting from the fact that overall response levels were so low during retention, especially to the tone (Fig. $8 B$ ). When examining only the ACSF group, the highest correlations were for USV to context $(r=0.77 ; p<0.01)$ and tone $(r=0.73 ; p<0.01)$. Correlations for freezing were low because of an obvious ceiling effect during acquisition (Fig. $8 A$ ). However, it is the combined group correlations that are most relevant to the point of this analysis.

To persue further how much of the variance in retention could
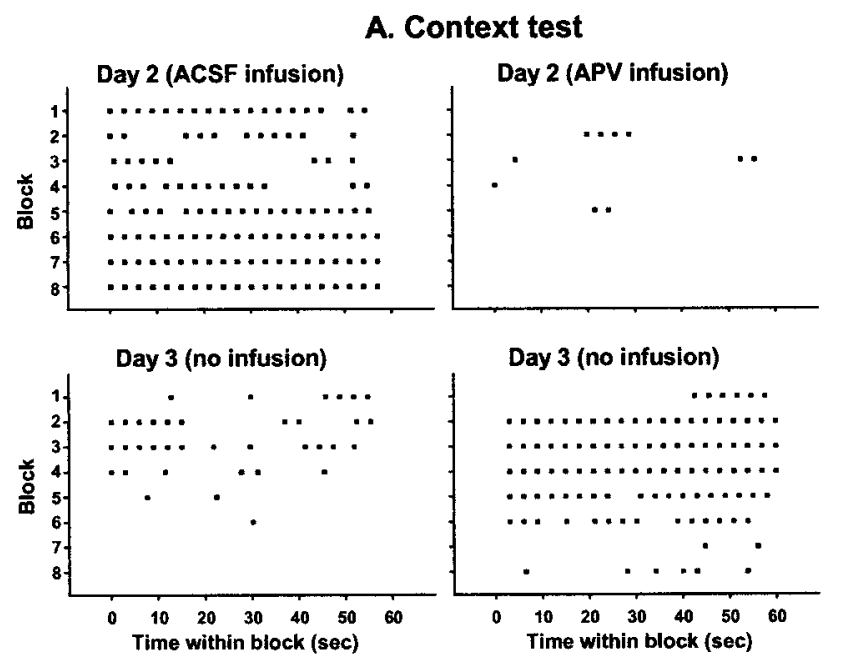

B. Tone test

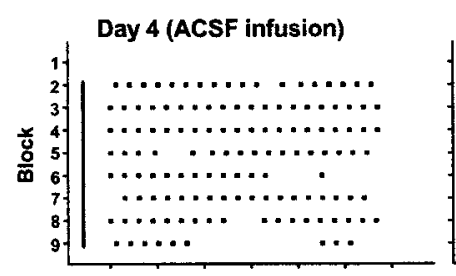

Day 4 (APV infusion)
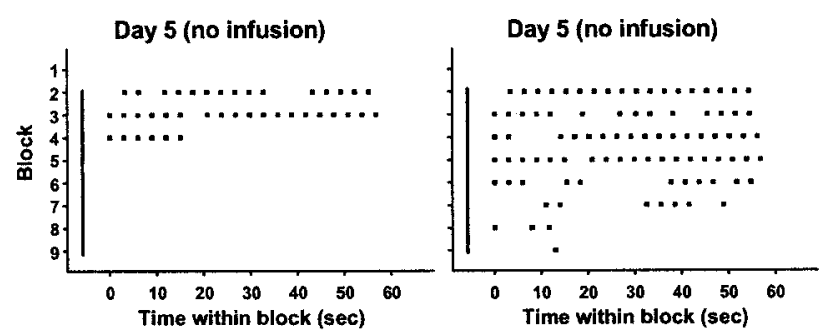

Figure 3. Examples of conditioned freezing raster plots indicating the distribution of freezing episodes from a typical ACSF and APV animal during context testing after infusions (Day 2) and context retesting without infusions (Day 3) $(A)$, and during tone-retention testing after infusions (Day 4) and tone retesting without infusions (Day 5) (B). The raster is divided into $1 \mathrm{~min}$ blocks in which each dot represents a time-stamped event of freezing.

be accounted for by postshock responding during training, we performed a multiple linear regression (using all three immediate postshock fear measures). The multiple correlation coefficients were as follows: freezing to context $(r=0.86 ; p<0.01)$ (accounting for $74 \%$ of the variance in retention), vocalization to context $(r=0.75 ; p<0.01)$ (accounting for $56 \%$ of the variance in retention), defecation to context $(r=0.75 ; p<0.01)$, freezing to tone $(r=0.66 ; p<0.05)$, vocalization to tone $(r=0.70 ; p<0.05)$, and defecation to tone $(r=0.70 ; p<0.05)$.

\section{DISCUSSION}

\section{APV action during retention testing}

The first experiment demonstrated that, on several response measures, NMDA receptors in the amygdala are critically involved in the expression of conditioned fear. Specifically, we found that intra-amygdalar infusions of APV before context- and tone-retention tests significantly interfered with the expression of conditioned fear, as assessed by USV, defecation, analgesia, and freezing (Figs. 2-7). When combined with previous findings 


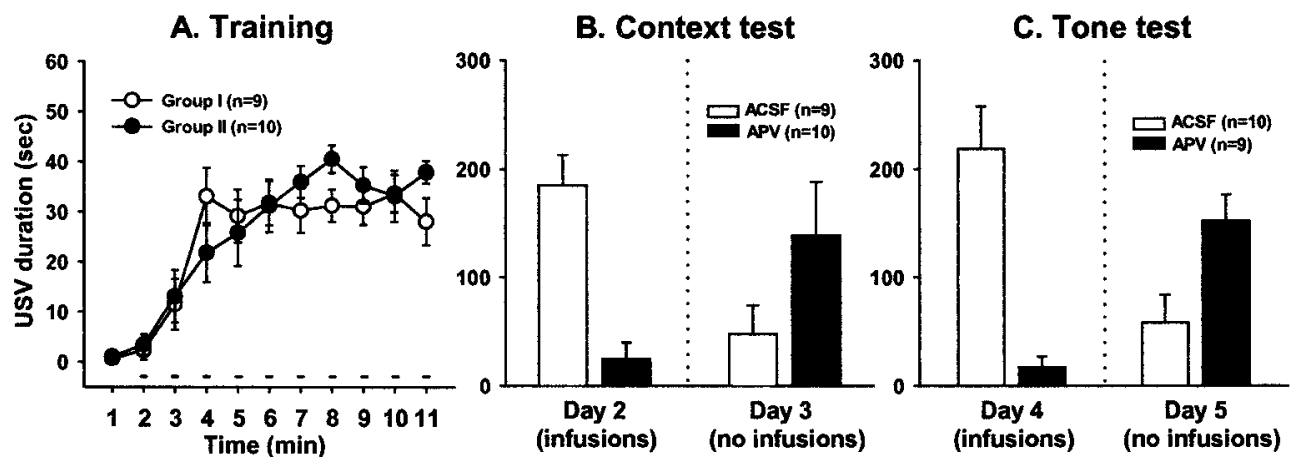

Figure 4. A, Mean duration of USV ( \pm SE) during the $1 \mathrm{~min}$ baseline and during the intervening 10 tone-shock pairings (denoted by small bars) of the 1 min ITIs with no inf usions. Group I received ACSF during the context test and APV during the tone test, whereas group II received APV during the context test and ACSF during the tone test. $B$, Mean duration of USV ( \pm SE) during 8 min of context testing after intra-BLA infusions of ACSF or APV (Day 2) and 8 min of context retesting the next day (Day 3). C, Mean duration of USV ( \pm SE) during the 8 min tone-retention test in context B after intra-BLA infusions of ACSF or APV (Day 4) and during the tone retest the next day (Day 5).

(Maren et al., 1996; Lee and Kim, 1998), we conclude that the impairing effects of intra-amygdalar APV on the expression of conditioned fear are wide-ranging across different CS modalities (tones, lights, contexts) as well as numerous fear responses (freezing, USV, defecation, analgesia). Not surprisingly, we also found APV effects on acquisition (experiment 2) and extinction of conditioned fear (experiment 1).

There are several mechanisms by which intra-amygdalar APV might affect the acquisition, expression, and extinction of conditioned fear (Table 2), five of which are considered here. The first possibility is that APV selectively, directly, and exclusively blocks the NMDAR-mediated synaptic plasticity involved in learning (acquisition and extinction) without affecting the normal synaptic transmission necessary to induce or express fear (possibility 1). In this case, APV should block acquisition and extinction but not the expression of conditioned fear. The present results, combined with other published findings (Chapman and Bellavance, 1992; Li et al., 1995; Maren et al., 1996; Lee and Kim, 1998), are sufficient to reject this possibility, at least in the most general case.

Three other possibilities are that intra-amygdalar APV significantly affects synaptic transmission in the amygdala along the CS pathway (possibility 2), the unconditioned stimulus (US) pathway (possibility 3), or both CS and US pathways (possibility 4). Finally, we could consider the possibility that APV has a purely motoric effect, because of altered synaptic transmission, which is downstream from all learning-related mechanisms (possibility 5). Recall that Lee and Kim (1998) did make reference to APV effects on CR centers, which could be interpreted in a manner similar to this last possibility.

According to possibility 3, conventional thinking suggests that intra-BLA APV should block acquisition (because of the blockade of US synaptic transmission) but not affect the expression or extinction of fear CRs. However, our results, along with those of others (Falls et al., 1992; Maren et al., 1996; Lee and Kim, 1998), also demonstrate that APV impairs both the expression and extinction of conditioned fear. Importantly, the present results demonstrate that APV impairs the expression of conditioned fear based on several response measures that were used to examine retention to both a tone and a context. We can thus reject the general hypothesis (possibility 3) that intra-BLA infusions of APV selectively and exclusively affect synaptic transmission in the US pathway.

Possibility 5 can easily be eliminated because it predicts no APV effect on acquisition or extinction and only a motor impair- ment in CR or unconditioned response (UR) production. The prediction is that APV only has an effect when present, and that this effect is to attenuate URs or CRs. In contrast, both possibility 2 and possibility 4 predict that APV should block the acquisition, expression, and extinction of conditioned fear, consistent with this study and other findings (Maren et al., 1996; Lee and Kim, 1998). A reasonable hypothesis is that APV affects fear conditioning, not only by preventing synaptic plasticity, but also or instead by impeding synaptic signaling of the CS and possibility also the US.

Recall that there is no convincing neurophysiological evidence that NMDA receptors are selectively involved in synaptic plasticity but not involved in normal synaptic transmission in the amygdala (LeDoux, 2000); however, there is evidence to the contrary (Chapman and Bellavance, 1992; Weisskopf and LeDoux, 1999), as in the visual cortex (Miller et al., 1989; Shatz, 1990). In the absence of additional data, the default assumption cannot be that amygdalar NMDARs generally participate only in plasticity but not normal synaptic transmission.

Considering these results, a weakened version of the Lee and Kim (1998) hypothesis might be that the expression of conditioned fear, as measured by the general paradigm developed by Brown et al. (1951), which entails conditioned enhancement of "pre-existing stimulus-response tendencies," is functionally unique. However, even this weakened version of this hypothesis has now been refuted by results from another laboratory. A recent study by Fendt (2001) showed that APV inf usions into the LA, which is located directly above the BLA, significantly attenuated the expression of both conditioned freezing and fearpotentiated startle [the same measure used by Davis and colleagues (Miserendino et al., 1990; Campeau et al., 1992; Gewirtz and Davis, 1997)]. It is possible that the discrepant findings with the expression of potentiated startle might be because of APV being infused into the LA (study by Fendt) rather than the BLA [studies by Davis and colleagues (Miserendino et al., 1990; Campeau et al., 1992; Gewirtz and Davis, 1997)]. It should be noted, however, that the expression of conditioned freezing is significantly impaired regardless of whether APV was infused into the BLA (Maren et al., 1996; Lee and Kim, 1998) (present study) or into the LA (study by Fendt). Interestingly, another laboratory has independently found that intra-BLA APV infusions significantly impaired the expression of conditioned (fear-related) defeat responses in hamsters (K. L. Huhman, personal communication). 


\section{A. Context test}

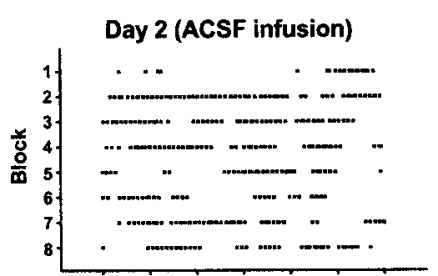

\section{Day 2 (APV infusion)}

. . .

$\cdot \cdot \cdot \cdot \cdot$

$\therefore \ldots$

$\cdot+\cdots$

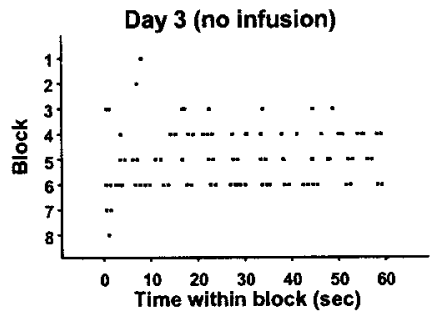

Day 3 (no infusion)

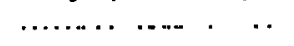

[................

-....................

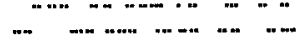

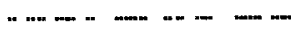

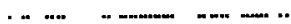
[.....................

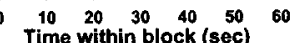

\section{B. Tone test}
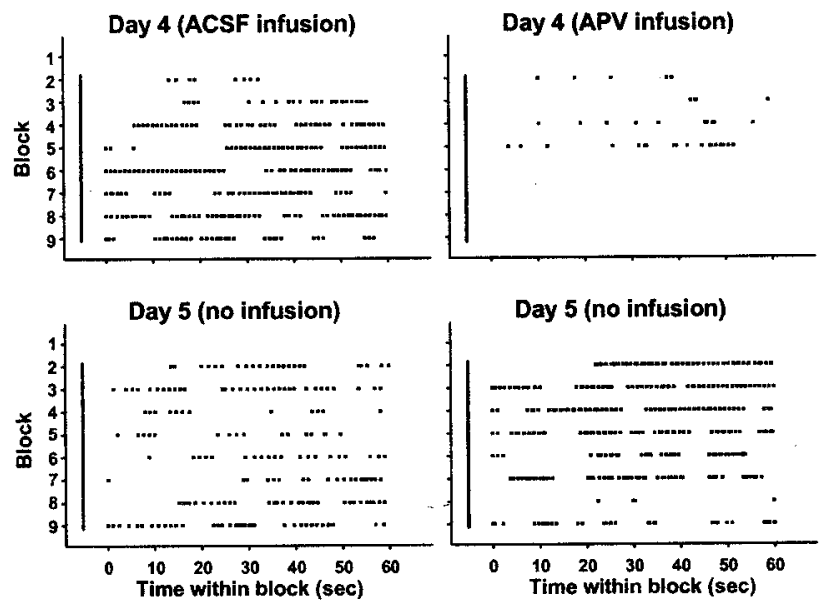

Figure 5. Examples of the USV raster plots in which each dot represents a time-stamped episode of vocalization. USV emissions are shown from a typical ACSF and APV animal during context testing after inf usions (Day 2 ) and context retesting without infusions (Day 3) $(A)$, and during tone-retention testing after infusions (Day 4$)$ and tone retesting without infusions (Day 5) (B).

Given the results of Fendt (2001), the Lee and Kim hypothesis cannot further accommodate the view of intra-amygdalar APV affecting the expression of conditioned fear, as measured by freezing, USV, defecation, and analgesia, but not startle. In the absence of strong and independent evidence to the contrary, we conclude that the fear-potentiated startle paradigm is not unique with respect to receptor mechanism or circuitry, but that there is something special about the particular procedures used by Davis and colleagues (Miserendino et al., 1990; Campeau et al., 1992; Gewirtz and Davis, 1997).

\section{APV action during training}

The second experiment demonstrated that the expression of postshock fear responses during training was also dramatically impaired by intra-amygdalar inf usions of APV when measured by freezing, USV, or defecation. The only other study to show this effect was done by Lee and Kim (1998), who used freezing as a response measure. That study was performed in an attempt to reconcile the discrepant data of Davis and colleagues (Miserendino et al., 1990; Campeau et al., 1992). The reasoning of Lee and

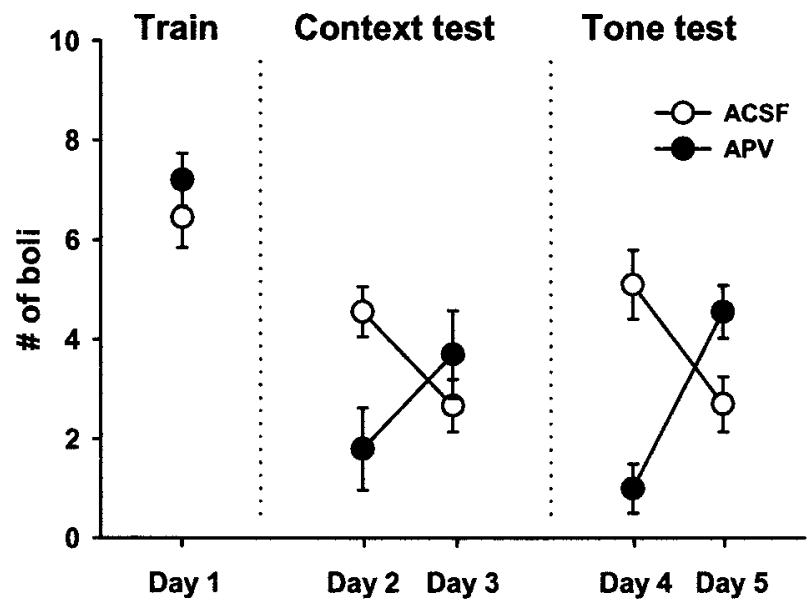

Figure 6. Mean number of boli $( \pm \mathrm{SE})$ during 10 tone-shock pairings (Day 1), an 8 min context-retention test after intra-BLA infusions of ACSF or APV (Day 2), an 8 min context retest (Day 3), an 8 min tone-retention test after intra-BLA infusions of ACSF or APV (Day 4), and an 8 min tone retest (Day 5). Open circles and filled circles represent the groups that received ACSF and APV, respectively, on days 2 and 4. (None of the groups received infusions on days 1, 3, and 5.)

Kim (1998) made three assumptions. The first was that APV might not block the expression of fear when the fear levels are very high. Second, they assumed the levels to be higher in the studies by Davis and colleagues (Miserendino et al., 1990; Campeau et al., 1992; Gewirtz and Davis, 1997). Finally, they reasoned that the fear levels should be higher during training than during subsequent retention tests. However, they did observe a strong APV effect on postshock freezing. We have now demonstrated the robustness and generality of their findings by switching to Sprague Dawley rats and including multiple fear measures.

We also examined the relationship between postshock fear responses and subsequent performance on retention tests, mainly because this relationship had not been examined previously and it seemed potentially relevant to the interpretation of the postshock fear responses and therefore the mechanisms of action of APV. What we found was that the immediate postshock expression of our three response measures during training was highly predictive

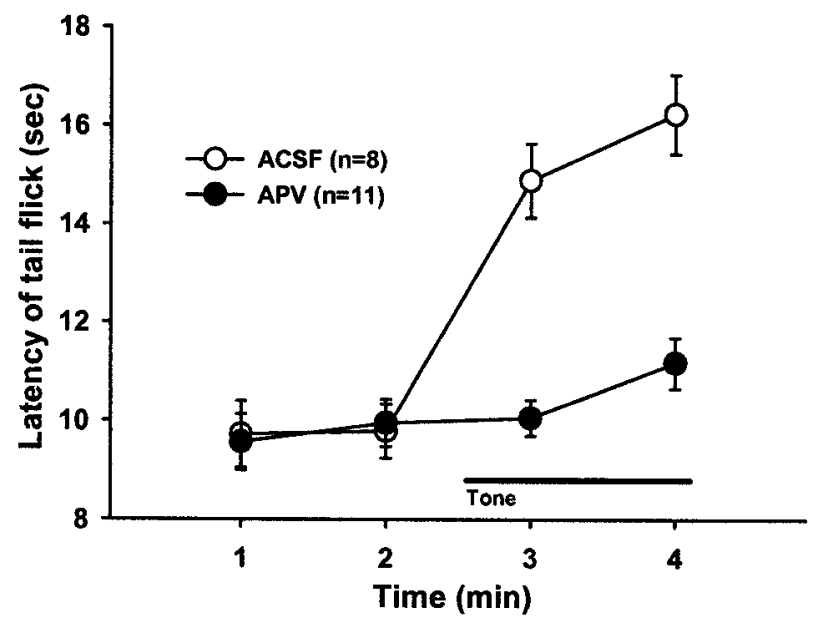

Figure 7. Mean tail flick latencies $( \pm \mathrm{SE})$ of animals during the baseline measures (minutes 1 and 2) and the tone presentation (indicated by a horizontal line) (minutes 3 and 4 ), after receiving intra-BLA infusions of ACSF or APV. 


\section{A. Training with infusions}
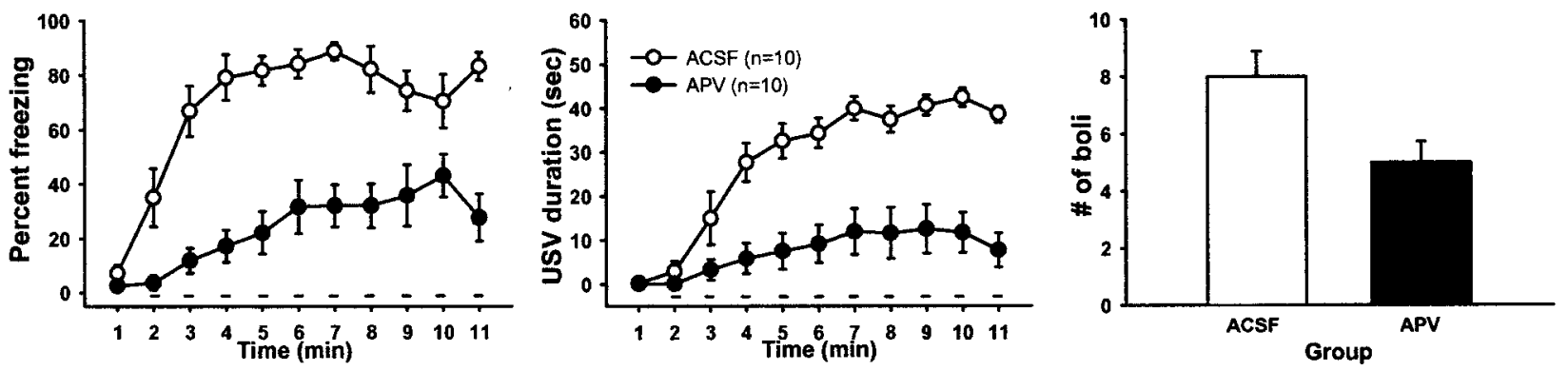

\section{B. Testing without infusion}
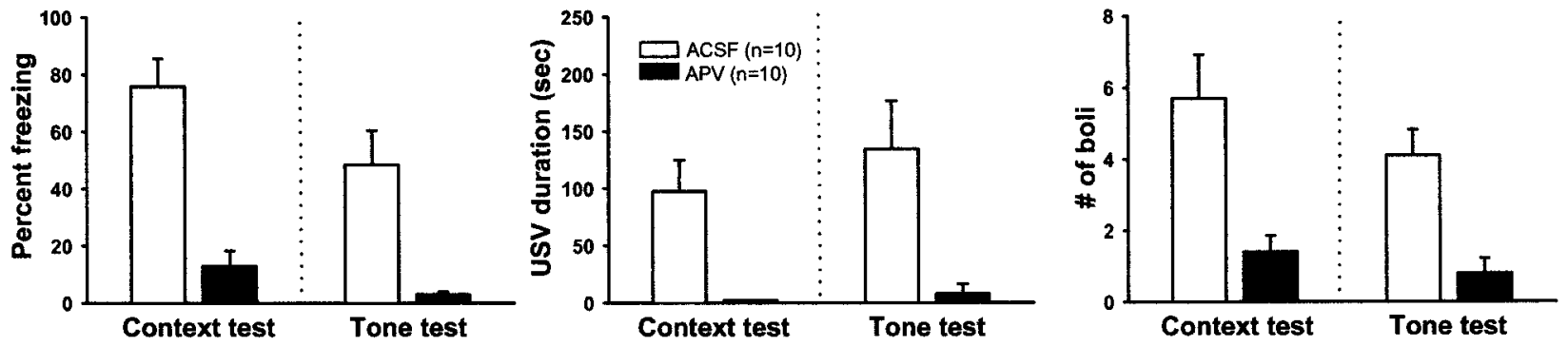

Figure 8. A, Mean percentage of freezing (left) and duration of USV (middle) ( \pm SE) during the 1 min baseline and during the intervening 10 tone-shock pairings (denoted by small bars) of the 1 min ITIs after intra-BLA infusions of ACSF or APV, and mean number of boli (right) ( \pm SE) during training. $B$, Mean percentage of freezing and duration of USV, and mean number of boli ( \pm SE) during context testing on day 2 and tone testing on day 3 .

\begin{tabular}{|c|c|c|c|c|c|c|}
\hline $\begin{array}{l}\text { Possible } \\
\text { effects }\end{array}$ & $\begin{array}{l}\text { CS synaptic } \\
\text { transmission }\end{array}$ & $\begin{array}{l}\text { US synaptic } \\
\text { transmission }\end{array}$ & $\begin{array}{l}\text { Synaptic } \\
\text { plasticity }\end{array}$ & $\begin{array}{l}\mathrm{CS}-\mathrm{US} \\
\text { acquisition }\end{array}$ & $\begin{array}{l}\mathrm{CS} \rightarrow \mathrm{CR} \\
\text { expression }\end{array}$ & $\mathrm{CS} \rightarrow \rightarrow$ extinction \\
\hline 1 & No effect & No effect & Impairment & Impairment & No effect & Impairment \\
\hline 2 & Impairment & No effect & Impairment & Impairment & Impairment & Impairment \\
\hline 3 & No effect & Impairment & Impairment & Impairment & No effect & No effect \\
\hline 4 & Impairment & Impairment & Impairment & Impairment & Impairment & Impairment \\
\hline 5 & No effect & No effect & No effect & No effect & Impairment & No effect \\
\hline
\end{tabular}

of subsequent retention to both context and tone (see Results). This was demonstrated mainly through regression analysis but also by comparing group mean differences (Fig. 8). Whatever the immediate postshock fear responses reflect, they are surprisingly predictive of subsequent retention. Clearly more work is needed to interpret postshock fear responses.

\section{Meaning of discrepant findings}

Davis and colleagues (Miserendino et al., 1990; Campeau et al., 1992; Gewirtz and Davis, 1997) reported that intra-BLA APV blocks the acquisition but not the expression of a fear-potentiated startle response to both a light and tone CS (Miserendino et al., 1990; Campeau et al., 1992). Based on these reports, they concluded that APV affects synaptic plasticity but does not affect normal synaptic transmission. Clearly, their results are neither general nor robust, because several independent laboratories have determined, using a variety of response measures and varying conditions, that APV does affect the expression of first-order (CS-US) conditioning (present results) (Maren et al., 1996; Lee and Kim, 1998; Fendt, 2001) (K. L. Huhman, personal communication).

The question of whether APV affects the expression of first- order conditioning is critical to the inference that learning-related changes reside in the amygdala (Gewirtz and Davis, 1997). The latter inference assumes that APV blocks the acquisition and extinction of fear, but not normal synaptic transmission. The conclusion that APV does not affect normal synaptic transmission is based solely on the report that APV failed to significantly affect the expression of first-order conditioning (Miserendino et al., 1990; Campeau et al., 1992). As we have seen, this claim is not valid in any general sense and may be unique to some very specific aspect of the procedures used by these investigators. The same reservation applies to the claim that BLA infusion with APV blocks second-order $\left(\mathrm{CS}_{2}-\mathrm{CS}_{1}\right)$ conditioning at a concentration that does not affect the expression of first-order conditioning (Gewirtz and Davis, 1997).

The conclusion that learning-related changes must reside in the amygdala is derived from the fact that this is the locus of the cannula and from the belief that APV has no relevant effects on amygdalar function other than blocking synaptic plasticity. Clearly the latter conclusion is incorrect in a general sense. Even if one imagines that, in some constrained parameter space, APV has no effect on the expression of one measure of first-order 
conditioning, it does not follow that the synaptic transmission involved in second-order conditioning is unaffected. The latter inference cannot be the default assumption because the general results refute that position.

If fear conditioning occurs in some yet-to-be identified brain structure or structures that require interactions with the amygdala, as some have suggested (Cahill et al., 1999), and if intraamygdalar APV substantially interferes with the normal synaptic transmission of CS and possibly US information to the extraamygdalar structure or structures (recall discussion of Table 2), then fear conditioning could be blocked by APV infusion into the amygdala even if the actual learning occurs outside the amygdala. Nevertheless, it is also important to recognize that the fact that APV affects CS-US signaling transmission in the amygdala does not necessarily exclude the possibility of fear learning occurring within the amygdala, and possibly involving a specific subtype or subtypes of NMDA receptors (Rodrigues et al., 2000).

\section{Summary and conclusions}

We are forced to concede that the results of the APV experiments do not strengthen the hypothesis that an NMDAR-dependent form of associative LTP in BLA mediates fear conditioning (LeDoux, 2000). We have seen a robust effect of APV in impairing the expression of conditioned fear to both context and tone CSs, as assessed by freezing, USV, defecation, and analgesia. Similarly, other studies have found that intra-amygdalar APV impairs the expression of conditioned fear-potentiated startle (Fendt, 2001) and defeat responses (K. L. Huhman, personal communication). These data do not rule out a direct effect of APV on the acquisition or extinction of fear; however, as we have seen in generalizing the findings of Lee and Kim (1998), the results do suggest that APV interferes with normal synaptic transmission in the amygdala in a manner that could indirectly affect the mechanisms involved in fear conditioning.

\section{REFERENCES}

Barrionuevo G, Brown TH (1983) Associative long-term potentiation in hippocampal slices. Proc Natl Acad Sci USA 80:7347-7351.

Blanchard RJ, Blanchard DC (1969) Crouching as an index of fear. J Comp Physiol Psychol 67:370-375.

Blanchard RJ, Blanchard DC, Agullana R, Weiss SM (1991) Twentytwo $\mathrm{kHz}$ alarm cries to presentation of a predator, by laboratory rats living in visible burrow systems. Physiol Behav 50:967-972.

Brown JS, Kalish HI, Farber IE (1951) Conditioned fear as revealed by magnitude of startle response to an auditory stimulus. J Exp Psychol 41:317-328.

Brown TH, Ganong AH, Kairiss EW, Keenan CL, Kelso SR (1989) Long-term potentiation in two synaptic systems of the hippocampal brain slice. In: Neural models of plasticity (Byrne JH, Berry WO, eds), pp 266-306. New York: Academic.

Brown TH, Kairiss EW, Keenan CL (1990) Hebbian synapses: biophysical mechanisms and algorithms. Annu Rev Neurosci 13:475-511.

Cahill L, Weinberger NM, Roozendaal B, McGaugh JL (1999) Is the amygdala a locus of "conditioned fear"? Some questions and caveats. Neuron 23:227-228

Campeau S, Miserendino MJ, Davis M (1992) Intra-amygdala infusion of the $N$-methyl-D-aspartate receptor antagonist AP5 blocks acquisition but not expression of fear-potentiated startle to an auditory conditioned stimulus. Behav Neurosci 106:569-574.

Chapman PF, Bellavance LL (1992) Induction of long-term potentiation in the basolateral amygdala does not depend on NMDA receptor activation. Synapse 11:310-318.

Chapman PF, Kairiss EW, Keenan CL, Brown TH (1990) Long-term synaptic potentiation in the amygdala. Synapse 6:271-278.

Clugnet MC, LeDoux JE (1990) Synaptic plasticity in fear conditioning circuits: induction of LTP in the lateral nucleus of the amygdala by stimulation of the medial geniculate body. J Neurosci 10:2818-2824.

Collingridge GL, Kehl SJ, McLennan H (1983) Excitatory amino acids in synaptic transmission in the Schaffer collateral-commissural pathway of the rat hippocampus. J Physiol (Lond) 334:33-46.

Davis M, Falls WA, Campeau S, Kim M (1993) Fear-potentiated startle: a neural and pharmacological analysis. Behav Brain Res 58:175-198.
Falls WA, Miserendino MJ, Davis M (1992) Extinction of fearpotentiated startle: blockade by infusion of an NMDA antagonist into the amygdala. J Neurosci 12:854-863.

Fanselow MS, Kim JJ (1992) The benzodiazepine inverse agonist DMCM as an unconditional stimulus for fear-induced analgesia: implications for the role of $\mathrm{GABA}_{\mathrm{A}}$ receptors in fear-related behavior. Behav Neurosci 106:336-344.

Fanselow MS, Kim JJ (1994) Acquisition of contextual Pavlovian fear conditioning is blocked by application of an NMDA receptor antagonist D,L-2-amino-5-phosphonovaleric acid to the basolateral amygdala. Behav Neurosci 108:210-212.

Fendt M (2001) Injections of the NMDA receptor antagonist AP-5 into the lateral nucleus of the amygdala block the expression of fearpotentiated startle and freezing. J Neurosci 21:4111-4115.

Gewirtz JC, Davis M (1997) Second-order fear conditioning prevented by blocking NMDA receptors in amygdala. Nature 388:471-474.

Grover LM, Teyler TJ (1990) Two components of long-term potentiation induced by different patterns of afferent activation. Nature 347:477-479.

Harris EW, Cotman CW (1986) Long-term potentiation of guinea pig mossy fiber responses is not blocked by $N$-methyl-D-aspartate antagonists. Neurosci Lett 70:132-137.

Hebb DO (1949) The organization of behavior: a neuropsychological theory. New York: Wiley.

Helmstetter FJ, Bellgowan PS (1993) Lesions of the amygdala block conditional hypoalgesia on the tail flick test. Brain Res 612:253-257.

Huang YY, Kandel ER (1998) Postsynaptic induction and PKAdependent expression of LTP in the lateral amygdala. Neuron 21:169-178.

Johnston D, Williams S, Jaffe D, Gray R (1992) NMDA-receptorindependent long-term potentiation. Annu Rev Physiol 54:489-505.

Kelso SR, Brown TH (1986) Differential conditioning of associative synaptic enhancement in hippocampal brain slices. Science 232:85-87.

Kelso SR, Ganong AH, Brown TH (1986) Hebbian synapses in hippocampus. Proc Natl Acad Sci USA 83:5326-5330.

Kim JJ, DeCola JP, Landeira-Fernandez J, Fanselow MS (1991) $N$-methyl-D-aspartate receptor antagonist APV blocks acquisition but not expression of fear conditioning. Behav Neurosci 105:126-133.

Lam YW, Wong A, Canli T, Brown TH (1996) Conditioned enhancement of the early component of the rat eyeblink reflex. Neurobiol Learn Mem 66:212-220.

LeDoux JE (2000) Emotion circuits in the brain. Annu Rev Neurosci 23:155-184.

Lee H, Kim JJ (1998) Amygdala NMDA receptors are critical for new fear learning in previously fear-conditioned rats. J Neurosci 18:8444-8454

Li X, Phillips RG, LeDoux JE (1995) NMDA and non-NMDA receptors contribute to synaptic transmission between the medial geniculate body and the lateral nucleus of the amygdala. Exp Brain Res 105:87-100.

Maren S, Fanselow MS (1996) The amygdala and fear conditioning: has the nut been cracked? Neuron 16:237-240.

Maren S, Aharonov G, Stote DL, Fanselow MS (1996) $N$-methyl-Daspartate receptors in the basolateral amygdala are required for both acquisition and expression of conditioned fear in rats. Behav Neurosci 110:1365-1374.

Miller KD, Chapman B, Stryker MP (1989) Visual responses in adult cat visual cortex depend on $N$-methyl-D-aspartate receptors. Proc Natl Acad Sci USA 86:5183-5187.

Miserendino MJ, Sananes CB, Melia KR, Davis M (1990) Blocking of acquisition but not expression of conditioned fear-potentiated startle by NMDA receptor antagonists in the amygdala. Nature 345:716-718.

Morris RG, Davis S, Butcher SP (1990) Hippocampal synaptic plasticity and NMDA receptors: a role in information storage? Philos Trans R Soc Lond B Biol Sci 329:187-204.

Paxinos G, Watson C (1997) The rat brain in stereotoxic coordinates, Ed 3. San Diego: Academic.

Rodrigues SM, LeDoux JE, Morrison JH (2000) Differential expression of the $N$-methyl-D-aspartate receptor NR2B subunit in the lateral nucleus divisions of the rat amygdala. Soc Neurosci Abstr 26:465.11.

Roozendaal B, McGaugh JL (1997) Glucocorticoid receptor agonist and antagonist administration into the basolateral but not central amygdala modulates memory storage. Neurobiol Learn Mem 67:176-179.

Shatz CJ (1990) Impulse activity and the patterning of connections during CNS development. Neuron 5:745-756.

Shors TJ, Mathew PR (1998) NMDA receptor antagonism in the lateral/ basolateral but not central nucleus of the amygdala prevents the induction of facilitated learning in response to stress. Learn Mem 5:220-230.

Teyler TJ, DiScenna P (1987) Long-term potentiation. Annu Rev Neurosci 10:131-161.

Weisskopf MG, LeDoux JE (1999) Distinct populations of NMDA receptors at subcortical and cortical inputs to principal cells of the lateral amygdala. J Neurophysiol 81:930-934.

Zalutsky RA, Nicoll RA (1990) Comparison of two forms of long-term potentiation in single hippocampal neurons. Science 248:1619-1624. 